\title{
THE ROLE OF TECHNOLOGY IN BUILDING A COMPETITIVE ADVANTAGE - PROGRAMMATIC BUYING AND ITS IMPACT ON THE COMPETITIVENESS OF AN ORGANIZATION
}

\author{
Robert Kozielski, Ph.D., Associate Professor \\ Nikodem Sarna, MSc \\ University of Lodz, Faculty of Management, Marketing Department \\ Matejki 22/26, 90-237 Łódź, Poland \\ 1e-mail: robert.kozielski@uni.lodz.pl \\ ORCID: 0000-0002-0200-1504 \\ 2e-mail:nikodem10@gmail.com \\ ORCID: 0000-0002-7105-4108
}

Received 13 January 2020, Accepted 22 March 2020

\begin{abstract}
Research background: Recent years have brought a real explosion of new tools and methods of conducting market activities based on new technologies. Solutions based on new technologies carry great development potential for an organization. There is a belief that new technologies - in particular, programmatic buying (analyzed in this article) - also impact an organization's ability to compete. Programmatic buying (PB) is a tool but also a new model of sales and purchase of advertising, under which the current package approach (traditional) has been replaced by a fully automated individualized approach.

Purpose: The aim of the article is to assess the impact of technology on an organization's ability to compete with the example of PB.

Research methodology: The empirical basis is both qualitative and quantitative research conducted in 2018-2019.

Results: The empirical material provides the basis for rejecting the main research hypothesis which claims that the usage of PB increases the effectiveness and efficiency of advertising and thanks to this on a companies' ability to compete. $\mathrm{PB}$ has a positive impact only on the effectiveness and efficiency of graphic ads. The same relation was not observed in terms of video ads. Nevertheless the results are not clear. It is recommended to deepen the analysis.

Novelty: Due to the fact that programmatic buying is a relatively new technologic solution there is no research that proves its impact on the marketing activities efficiency as well as its role in building the competitive advantage of a company, especially on the Polish or European market. This research starts
\end{abstract}


the discussion of the role of PB in companies' market activities and fits in the dispute of the significance of new technologies.

Keywords: competitive advantage, strategy, technology, advertising, advertising efficiency, advertising effectiveness, programmatic buying

JEL classification: M10, M31, M37

\section{Introduction}

The ability to build a competitive advantage is a key area of interest for management sciences. It becomes even more substantial in times of turbulent changes (Ansoff, 1985), nowadays known as VUCA (Gilman, 2017). In times of paradoxes, discontinuities and shortterm changes, the challenge is not only to predict the future (Płoszajski, 2005) but, above all, to maintain a competitive advantage - in particular, when we consider the extent to which companies lose their market position and the shortening life cycle of organizations. As reported in the years 1956 to 1981, 24 Fortune 500 companies went bankrupt. In the years 1982 to 2006 , there were already 40 of them per year (Colvile, 2017). At present, it is predicted that $40 \%$ of companies currently listed on the Fortune 500 list will not survive in the next 2 to 3 years (Ismail, Malone, Van Geest, Diamandis, 2014). This means that, on average, half of organizations today are not able to survive for more than a decade; only $15 \%$ have been on the market for more than 30 years and 5\% for more than 50 years (Feser, 2011).

The increase in the complexity and variability of organization management today is largely the result of not only globalization processes but, above all, the development of technology (Kelly, 2017). Technology can affect the tactical activities of an organization but also competitive strategies and organizational culture. It may, therefore, impact on three key levels of building a competitive advantage.

Recent years have brought a real explosion of new tools and methods of conducting market activities based on new technologies. These include, for example, sentiment analysis, predictive methods, artificial intelligence, machine learning, geotargeting, content management, beacons, blockchain, VR AR and many others. One such solution is programmatic buying used in the process of purchasing online advertising media in real-time. The aim of the article is to assess the impact of technology on an organization's ability to compete with the example of programmatic buying. The empirical basis is qualitative and quantitative research conducted in 2018-2019. 
The article consists of three main parts - a theoretical introduction which will present three key levels of competition, the importance of technology for competing between contemporary organizations and the essence and application of programmatic buying. The second part is a presentation of the methodology and research results. The entire work is recapped by the identification of key conclusions, recommendations and future research directions.

\section{Levels of competition}

An attempt to view research and publications in the field of management sciences, from a certain distance, confirms that management can be viewed from a tactical, strategic and cultural perspective (Webster, 2002). The first concerns mainly methods and tools used in management. Therefore, research and publications focus on describing the possibilities of their use, assessing their application as well as the benefits and threats they may cause. The second covers strategic issues related to the organization's activities. Although today the value of the word 'strategy' has undergone some depreciation, mainly through its widespread and often thoughtless use, we are still intuitively - not to mention the definition sphere - able to distinguish the word from both the operational and cultural levels. It includes systems and processes that lead to the definition of long-term goals, target groups and markets, ways of competing and the allocation of organizational resources. Finally, the third level concerns the philosophy of the organization. It is usually associated with the culture of the organization, its approach and organizational thinking. This is the attitude the organization represents and its way of thinking. These three levels are described in Figure 1.

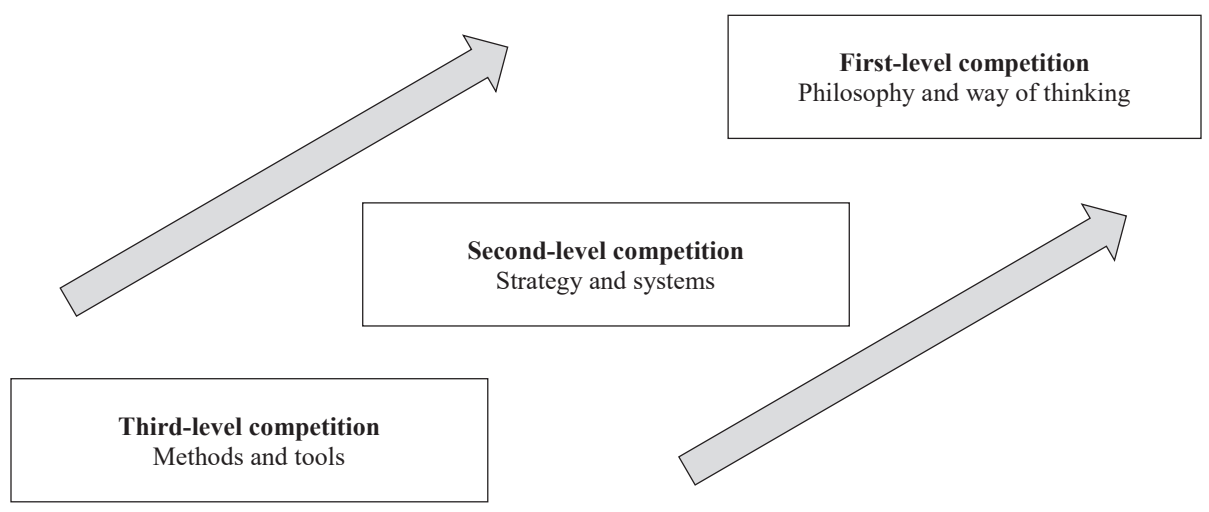

Figure 1. Three levels of competition

Source: Kozielski, Mardosz and Matuszewska (2017). 
Based on the classification made, three key sources of a competitive advantage can be defined. The most basic, but also the easiest to copy, is the one that only includes the ability to efficiently use tools or methods (third-level competition). The list of possible tools and methods is very wide. They may relate to various areas of the organization's activity - HR (e.g. employer branding), accounting (e.g. target costing method), sales (e.g. loyalty programs), logistics (e.g. the ABC method) but also marketing (e.g. guerrilla marketing). The risk of losing a competitive advantage - if, at all, the organization is able to achieve it at this level - is very high. It is therefore worth making an effort to build the organization's competitiveness at the second and first level. The second level includes the ability to build valuable strategies, unique business models and effective systems of competition. The unique strategy is equipped with an efficient set of internal processes. It is no longer a single method or tool but a comprehensive mechanism. Examples include the blue ocean strategy or lean management. The most durable formula for competing is level one. It is level one where methods and tools, strategy and systems are supplemented with the appropriate organizational culture, organizational attitude or organizational thinking. KAIZEN's philosophy, customer-centric orientation or the idea of teal organizations can serve as an example here.

\section{New technologies and their importance for the competitive ability of an organization}

The subject of an organization's ability to compete is directly related to the essence of competitive advantage. It is not the purpose of this article to review the different approaches to defining this concept. Nevertheless, it is necessary to indicate the viewpoint adopted in the article. According to that, competitive advantage is understood in terms of the market, competitors and customers (Koźmiński, Piotrowski 1998; Winer, Dhar, 2011) and the results obtained (Stoner, Freeman, Gilbert, 2001). Therefore, competitive advantage leads to obtaining results above average and is implemented by providing clients with better value and benefits than those offered by competitors (Doyle, Stern, 2006).

Solutions based on new technologies carry great development potential for the organization. There is a belief that we are now at the threshold of an era, referred to as the second technological era (Brynjolfsson, McAfee, 2015) or the fourth industrial revolution (Schwab, 2016) in which the use of computers is not only widespread but also includes areas in which they did not apply 12 to 15 years ago. The presence of a network environment (computers with Internet access, mobile Internet) means that it is possible to combine the intellectual work of billions of brains 
and machines, thanks to which we are dealing with a significant simplification of economic processes but also new forms of competition, business models and organizational formulas.

New technologies shape almost all contemporary reality, not just business. The growing pace of their development leads to far-reaching changes in the physical, digital and biological dimensions. These, inturn, translateintotheconditionsinwhichthebusinessoperates. Contemporary enterprises operate in an extremely volatile and hardly predictable environment, but on the other hand, they face a huge opportunity - the availability of data, the presence of the Internet and the increasing degree of process automation. The transformation of business models towards more open solutions and involving network communities, as well as minimizing the value attributed to physical copies of the product for the sake of sharing them as a service and building value through sales-related and customer service activities, are of great importance.

The programmatic buying technology adopted for the purposes of the article corresponds strongly with both marketing and market activities and is the implementation of at least several key aspects - the automation of selected processes, decision making based on data, or the progressive individualization of activities resulting from the increasing amount of knowledge about customers. From a strategic point of view, it perfectly fits into trends induced by technological development. On the other hand, as one of the tools used in everyday practice, it complements the set of modern marketing instruments. This becomes particularly important when we consider the fact that this and other technologies can affect the competitive advantage of an organization at all three levels. At the level of tools and methods (level three), for example, by the availability of tools to track marketing activities on the Internet, the focus shifts towards their result - it becomes the key point. At the strategic level (level two), this may include process orientation (the importance of the continuity of activities and the full availability of the people and resources involved), the multidimensionality of activities expressed in undertaking many different marketing projects at the same time or integrating many instruments and activities to influence the client in a multifaceted manner hence obtaining synergy (Bishop, 2001). New technologies - in particular, programmatic buying (analyzed in this article) - also impact the organization's ability to compete at the first level mainly by focusing on the customer, even by striving to eliminate information asymmetry and the need to understand customer behavior (Mazurek, 2012). 


\section{Programmatic buying - idea and its application}

Programmatic buying is a tool but also a new model of sales and purchase of advertising (Allen, 2016), under which the current package approach (traditional) has been replaced by a fully automated individualized approach. This approach often uses advanced auction models in the process of separately valuing each available view from a viewpoint of various goals and conditions. It also takes into account fluctuations in supply and demand for a given advertising inventory.

Programmatic buying is generally a tool although it can be treated much more widely as a concept of action - the emergence of which was preceded by the evolution of other solutions shaping the face of the modern advertising market, primarily Internet advertising. Programmatic buying was created and operates in an environment of a large number of new solutions accompanying modern online advertising. These are primarily the so-called "big data" (Marr, 2017) and graphic advertising using data that directly relates to the issue of the growing importance of data - data from the point of view of decisions taken in the area of buying space in the media and the selection of advertising creations as well as the so-called "machine learning" (Brownlee, 2013) and "prospecting" (O'Kane, 2012). These are closely related to the growing processing capacity in the field of statistical data processing. It may be evidently observed that a common feature is the use of technology and data supported by artificial intelligence whose goal is to further improve the efficiency of advertising activities taking place in real-time.

Programmatic buying is believed to address the two most important problems. Firstly, the lack of transparency in terms of an ads visibility to users as well as the lack of buyers ability to estimate the real value of each and every ad impression. Secondly, price pressure translating into the need to constantly improve efficiency and effectiveness (Bush, 2016).

Programmatic buying technology functions in the sphere of advertising, primarily online, although it does not have to be limited to it. Attempts to apply it to other media have been made for some time, often with a positive result - this matter will be analysed at the end of this section. The most important distinctive features of programmatic buying compared to the traditional model of media buying are (Bush, 2016):

1. Granularity i.e. the ability to purchase each individual ad impressions separately - not in blocks or packages, as is the case with direct cooperation with the publisher - as well as when using advertising network services.

2. The ability to make decisions about the purchase of selected ad impressions in realtime i.e. thanks to a millisecond evaluation and decision to take action that takes place 
when there is a chance to buy. This opportunity is created at the moment of loading the website, where advertising slots that can be used are located. The number of such opportunities during the day is expressed from tens of millions to hundreds of billions depending on the scale. Their service therefore requires a strong processing capacity.

3. The availability of real-time information about potential advertising i.e. the amount of available inventory under certain assumptions.

4. The ability to manipulate the creative and advertising message on an ongoing basis based on information about the purchased ad view and the user who will be able to see this ad.

5. The automation of the process of purchasing advertising inventory and serving creatives in the purchased space.

Programmatic buying is therefore a technology focused on improving the efficiency and effectiveness of advertising activities carried out by advertisers, agencies, media houses and other entities purchasing media as well as improving the effectiveness of the advertising inventory sales process for publishers. The key to achieving this goal is primarily the automation of campaign management and media buying, the extensive use of user data and optimization algorithms as well as improvements in the updating and customizing advertising creatives.

\section{Research methodology}

The adopted definition and understanding of programmatic buying indicates the impact of this solution on an organization's ability to compete primarily on the third level (methods and tools). Nevertheless, its impact on the other two levels of competition is noticeable. This narrow approach was adopted for empirical purposes and, as a result, the aim of the study was to assess the impact of programmatic buying on the effectiveness and efficiency of advertising and thus on the organization's ability to compete on the third level (Figure 1). The logic of the approach is based on the belief that the use of new technologies - in this case, programmatic buying - allows the efficiency and effectiveness of marketing activities to increase and thus affect the higher ability of the organization to compete. As a result, the hypothesis subject to examination was the statement that programmatic buying contributes to improving the efficiency and effectiveness of advertising in the field of graphic and video advertising and, through this, to the organization's ability to compete. It should be mentioned that effectiveness has been defined as "the degree of achievement of goals" and efficiency is understood as "getting better results 
at a minimum of the same costs by one of the methods of media buying compared to the other (traditional versus using programmatic buying) or the same results at lower costs".

The starting point of the research process was qualitative research and preliminary quantitative research. Qualitative research was conducted using the method of personalized in-depth interviews (IDI) in the period from April to May 2018 on a group of nine experts. Two represented the academic community; three media house employees, two people cooperating with technology providers and two representatives of publishers of both traditional but also digital media. The experts were chosen based on their expertise and readiness to share their standpoints. It is worth mentioning here that about $80 \%$ of the funds allocated in Poland for online advertising purchased using programmatic buying are spent by the 10 largest media houses. These companies run the majority of Internet campaigns implemented using the analyzed technology hence the selection of the sample was intentional. The study included questions about both video and graphic advertising and the assessment criteria were CPC, CPA, CPM indicators (Kozielski, 2017). The conclusions of the qualitative research have already been presented (Sarna, 2019) and will only be mentioned herein. The analysis will focus on quantitative research.

The quantitative research (by the CAWI method) was carried out in 2019. Taking into account costs and ability to acquire data CAWI was chosen as the most relevant method. The sample included an analysis of 159 advertising campaigns. Campaigns using graphic advertising prevailed in the sample (142 units). Only 17 included video advertising. Regarding the key assessment index, campaigns with effectiveness measured by the CPM prevailed (98 elements), the second-largest campaigns were measured by the CPA (29 elements) and the least were the campaign evaluations aimed at provoking the user to click on the advertisement (CPC - 11 units). The effectiveness of all campaigns using video formats was measured by CPM. The mixed methods were applied to meet the triangulation requirement and reduce the data errors.

For the purposes of the study, research hypotheses - in addition to the main hypothesis - were adopted. They were based on the literature review and key conclusions taken from the qualitative research. The main hypothesis expresses the belief that the use of the programmatic model is characterized by higher effectiveness and efficiency than the purchase of media in the traditional model. The specific hypotheses included the following statements:

H1: The use of programmatic buying in the field of display advertising is more effective than in the case of the traditional model. 
$\mathrm{H} 2$ : The use of programmatic buying in the field of display advertising is more efficient than in the case of the traditional model.

H3: The use of programmatic buying in the field of video advertising is more effective than in the case of the traditional model.

H4: The use of programmatic buying in the field of video advertising is more efficient than in the case of the traditional model.

The empirical basis of the analyses presented in the article is the data from the first stage regarding the assessment of the effectiveness and efficiency of the campaign without reference to individual measurement indicators. This is mainly due to limitations regarding the volume of the article.

\section{Assessment of the impact of programmatic buying on the competitiveness of an organization}

Assessment of the impact of programmatic buying on the effectiveness and efficiency of online advertising and thus on the competitiveness of the organization was carried out as part of qualitative research in two dimensions - the general opinion (based on the experience of the respondents) regarding conducted traditional campaigns and those using programmatic buying and in relation to types of advertising (graphic and video) and evaluation measures (CPM, CPC, CPA). The data collected as part of qualitative research provide the basis for the statement that the impact of implementing the programmatic buying model on the effectiveness and efficiency of advertising activities is clearly positive in the respondents' opinion (Sarna, 2019). When asked about the reasons for this situation, the study participants highlighted the key characteristics of programmatic buying:

- extensive use of data on Internet users,

- automation of the process of buying the media, which allows limiting the amount of manual work,

- granularity and precision of purchase reduced to the level of a single advertising view.

The encouraging results of qualitative research prompted quantitative research. First, the existence of differences in the effectiveness and efficiency of the traditional model and programmatic buying broken down into the advertising format was verified. Prior to the commencement of the actual analyses, normality was verified by calculating their skewness and kurtosis values and then by conducting the Kolmogorov-Smirnov test (Blalock, 1975). The distribution of the effectiveness of campaigns using graphic advertising was characterized 
by a skewness value of -0.790 and a kurtosis value of -0.294 , meaning both values were in the range $<-1.1>$ (Bollen, 1989). Despite this, the asymptotic significance obtained in the Kolmogorov-Smirnov test was 0.000 , which means that this distribution cannot be considered as normal. In the case of the effectiveness of campaigns using video advertising, skewness and kurtosis were -0.899 and 0.434 respectively i.e. in the range $<-1.1>$ while the asymptotic significance obtained as a result of the Kolmogorov-Smirnov test was 0.117 , which means that this distribution could theoretically be considered as normal. However, the small sample size, which amounted to 17 elements, prevents the application from being finally recognized as entitled. Due to the lack of premises allowing for the recognition of the above distributions as normal, the non-parametric U. Mann-Whitney test was used in further analyses (Makowski, 2019, pp. 199-201). For graphic advertising, the average performance scores were:

- 7.63 for campaigns conducted in the traditional model,

- 8.38 for campaigns conducted in the programmatic buying model.

The average for the graphic format was also higher for the programmatic buying model compared to the traditional model. The asymptotic significance, the most important from the point of view of the verification of differences between the models, reached a value of 0.036 i.e. below 0.05 . This means that in the light of the U. Mann-Whitney test, in the case of campaigns using graphic advertising, there are no grounds to reject the hypothesis that there is a statistically significant difference between the effectiveness of the programmatic buying model and the effectiveness of the traditional model and that it is higher in campaigns using this first media purchase model.

When it came to video advertising, the average performance ratings were:

- 7.50 for campaigns conducted in the traditional model,

- 8.73 for campaigns conducted in the programmatic buying model.

Here, the average rank was also higher in the case of the programmatic buying model. The asymptotic significance resulting from the U. Mann-Whitney test reached 0.233 , which means that in the case of video advertising there are no grounds to consider the differences between the effectiveness of campaigns conducted in the programmatic model and the effectiveness of campaigns conducted in the traditional model as statistically significant. This result is not consistent with the conclusions drawn from the literature analysis and previous stages of this study but it is also necessary to take into account the very small sample size in this particular subgroup. The statistical analysis on a sample of 17 elements is characterized by a high risk of error; therefore, it is worth considering this result as a guide for further in-depth research. 
In addition to the effectiveness analysis, the aspect of efficiency was also assessed. The distribution of efficiency of campaigns using graphic advertising was characterized by a skewness value of -0.658 and a kurtosis value of -0.131 hence both values were within the range of $<-1.1>$. Despite this, the asymptotic significance obtained in the KolmogorovSmirnov test was 0.000 , which means that this distribution cannot be considered as normal. In the case of the efficiency of campaigns using video advertising, the skewness and kurtosis values were -0.068 and 1.189 respectively; therefore, kurtosis is not within the range $<-1.1>$. On the other hand, however, the asymptotic significance obtained in the Kolmogorov-Smirnov test was 0.200 , which means that theoretically this distribution could be considered as normal. Nevertheless, the small sample size, which amounted to 17 elements, prevents this conclusion from being finally recognized as entitled.

Similarly to the verification of differences in the effectiveness of the compared models, the issue of differences in their efficiency was also verified using the U. Mann-Whitney test. There are no sufficiently strong reasons to consider the obtained distributions as normal. When it came to graphic advertising, average efficiency ratings were:

- 7.17 for campaigns conducted in the traditional model,

- 8.09 for campaigns conducted in the programmatic buying model.

The average rank for the traditional model was lower than for the programmatic buying model, while the asymptotic significance obtained as a result of the U. Mann-Whitney test was 0.002. As this value is less than 0.05 , it should be considered as giving grounds for the inability to reject the hypothesis that there is a statistically significant difference between the efficiency of the traditional model and the efficiency of the programmatic buying model. The efficiency of the programmatic model is higher.

When it comes to video advertising, the conclusions are similar to the matter of performance discussed earlier. The average efficiency ratings were as follows:

- 6.83 for campaigns using the traditional model,

- 8.09 for campaigns conducted in the programmatic buying model.

The average rank for the programmatic buying model was higher than the average rank for the traditional model. The asymptotic significance obtained as a result of the U. MannWhitney test was 0.154 (i.e. over 0.05 ), which does not provide grounds for considering the differences between the effectiveness of the programmatic buying model and the effectiveness of the traditional media purchase model in the case of video advertising as being statistically significant. This is not consistent with the results of the literature analysis or with the survey part 
of the CAWI research. It is, however, consistent with the analysis of the differences between the effectiveness of both models in campaigns using video advertising.

It was mentioned earlier that, within the collected sample, the efficiency of all campaigns which use video formats gives rise to a rejection of the hypothesis regarding the superiority of the programmatic model over the traditional model. However, one should approach this conclusion with caution and the incompatibility of the result obtained with literature and previous studies rather ought to be as a premise for further, more in-depth studies. The number of assessments of the effectiveness and efficiency of campaigns using video formats was only 17 , which means that the test result should be approached with a large dose of skepticism. More precise testing (i.e. limited to video formats and on a larger sample) may, therefore, be necessary.

\section{Conclusions and directions for further research}

The scale and pace of changes in the modern business environment are strongly correlated with adaptation processes. On the one hand, new technologies strengthen the dynamics of change and on the other allow organizations to respond to these changes and intensify adaptation processes. The turbulence of the business environment also affects the sustainability of competitive advantage. Programmatic buying is an example of technology that affects both the business environment of an organization. It allows enterprises to adapt to these market changes but also for an advantage over competitors to be gained. The conducted research did not give grounds for rejecting this attitude. It is true that the test results are not conclusive. Two hypotheses (H1, H2) cannot be rejected, but hypotheses H3 and H4 can. Consequently, the empirical material provides the basis for rejecting the main research hypothesis. It may be assumed that the rejection of $\mathrm{H} 3$ and $\mathrm{H} 4$ is mainly the result of a small sample. Nevertheless, this is only guesswork.

Therefore, it cannot be unequivocally assumed that new technologies (represented in the study by programmatic buying) translate into an increase in the competitiveness of the organisation in general and, in particular, at the third level (methods and tools). Although based solely on the opinions and experience of experts, such a relationship exists but it has not been fully confirmed empirically.

Considering the above, it is recommended to carry out tests on a larger sample of a quantitative nature in the future and, preferably, using different methods (triangulation). In addition, it is worth conducting future research which would cover diverse entities and campaigns implemented in various markets (services, trade, B2B, B2C, etc.). It is also worth 
researching not only to assess the ability to compete at level three but also to the extent possible at levels two and one.

\section{References}

Allen, R. (2016, May 21). What is Programmatic Marketing? [Web log message]. Retrieved from: http://www.smartinsights.com/internet-advertising/internet-advertising-targeting/ what-is-programmatic-marketing.

Ansoff, H.I. (1985). Zarządzanie strategiczne. Warszawa: PWE.

Bishop, B. (2001). Marketing globalny ery cyfrowej. Warszawa: PWE.

Blalock, H.M. (1975). Statystyka dla socjologów. Warszawa: PWN.

Bollen, K.A. (1989). Structural Equations with Latent Variables. New York, NY: John Wiley and Sons.

Brownlee, J. (2013, November 17). What is Machine Learning - A Tour of Authoritative Definitions and a Handy, One-Liner You Can Use [Web log message]. Retrieved from: http:// machinelearningmastery.com/what-is-machine-learning.

Brynjolfsson, E., McAfee, A. (2015). Drugi wiek maszyny - praca, postęp i dobrobyt czasach genialnych technologii. Warszawa: MT Biznes.

Colvile, R. (2017). The Great Acceleration: How the World is Getting Faster, Faster. London: Bloomsbury Publishing Plc.

Doyle, P., Stern, Ph. (2006). Marketing Management and Strategy. London: Prentice Hall.

Gilman, D. (2017). Outsmarting VUCA - Achieving Success in a Volatile, Uncertain, Complex, \& Ambiguous World. Charlesten: Advantage Media Group.

Ismail, S., Malone, M.S., Van Geest, Y., Diamandis, P.H. (2014). Exponential Organizations. New York, NY: Diversion Publishing.

Feser, C. (2011). Serial Innovators: Firms That Change the World. London: Wiley.

Kelly, K. (2017). The Inevitable: Understanding the 12 Technological Forces That Will Shape Our Future. London: Punguin Books.

Kozielski, R. (2017). Wskaźniki marketingowe. Warszawa: Wydawnictwo Nieoczywiste.

Kozielski, R., Mardosz, A., Matuszewska, A. (2017). Sukces rynkowy organizacji. Warszawa: Wydawnictwo Nieoczywiste.

Koźmiński, A.K., Piotrowski, W. (1998). Zarządzanie-teoria i praktyka. Warszawa: Wydawnictwo Naukowe PWN. 
Marr, B. (2017, June 15). 3 Massive Big Data Problems Everyone Should Know About [Web log message]. Retrieved from: https://www.forbes.com/sites/bernardmarr/2017/06/15/3massive-big-data-problems-everyone-should-know-about/\#338d24966186.

Mazurek, G. (2012). Znaczenie wirtualizacji marketingu w sieciowym kreowaniu wartości. Warszawa: Poltext.

O'Kane, C. (2012, February 8). Moving on from Retargeting: Why Prospecting in Display ss Good for the Industry [Web log message]. Retrieved from: https://www.exchangewire. com/blog/2012/02/08/moving-on-from-retargeting-why-prospecting-in-display-is-goodfor-the-industry.

Płoszajski, P. (ed.) (2005). Przerażony kameleon - eseje o przyszłości zarządzania. Warszawa: Fundacja Rozwoju Edukacji menedżerskiej SGH.

Sarna, N. (2019). Model Programmatic Buying a skuteczność i efektywność reklamy internetowej. Przeglad Nauk Ekonomicznych, 32, 55-66.

Schwab, K. (2016). The Fourth Industrial Revolution. London: Penguin.

Stoner, A.F., Freeman, R.E., Gilbert, D.R. (2001). Kierowanie. Warszawa: PWE.

Webster, F.E. (2002). Marketing Management in Changing Times. Marketing Management, $11(1), 18-23$.

Winer, R.S., Dhar, R. (2011). Marketing Management. New York, NY: Pearson. 